\title{
Composição Corporal, Composição do Ganho de Peso e Exigências Nutricionais de Novilhos de Origem Leiteira ${ }^{1}$
}

\author{
Evandro de Oliveira Rocha ${ }^{2}$, Carlos Augusto de Alencar Fontes ${ }^{3}$
}

\begin{abstract}
RESUMO - Este trabalho foi conduzido para estudar as exigências líquidas de energia para mantença e ganho de peso, as exigências líquidas de proteína para ganho e as dietéticas de proteína e energia, bem como as mudanças na composição corporal de novilhos de origem leiteira com o aumento do peso vivo, visando ao aproveitamento para produção de carne. Dezesseis novilhos, com idade e peso vivo iniciais médios de 20 meses e 202,0 kg, foram usados. Os animais foram divididos em cinco grupos: um grupo de animais foi abatido no início do experimento (AI), outro foi submetido à alimentação restrita (AR) e três receberam alimentação ad libitum (AL-1, AL-2 e AL-3), sendo abatidos ao atingirem os pesos vivos de 250,0; 300,0; e 350,0 kg, respectivamente. Os animais do grupo AR receberam níveis $15,0 \%$ acima das exigências de mantença de proteína e energia. A ração continha proporção volumoso:concentrado de 1:1 na matéria seca, com 12,48\% de proteína bruta. As exigências líquidas de energia para mantença (ELm) foram determinadas pela regressão do logaritmo da produção de calor em função do consumo de energia metabolizável, extrapolando-se para o nível zero de consumo de energia metabolizável. Equações de regressão do logaritmo dos conteúdos corporais de proteína, gordura e energia, em função do logaritmo do peso corporal vazio (PCVZ), ajustadas com base nos dados dos animais AI, AL-1, AL-2 e AL-3, possibilitaram estimar os conteúdos dos mesmos para qualquer PCVZ na faixa de peso estudada. Equações de predição para estimar a composição do ganho de PCVZ foram obtidas por derivação das equações de regressão. As exigências líquidas de energia de mantença estimada para os novilhos foram $68,44 \mathrm{kcal} / \mathrm{kg}^{0,75}$. As exigências líquidas de proteína estimada para ganho foram semelhantes às recomendadas pelo AFRC (1993). As exigências totais de energia metabolizável estimadas foram, aproximadamente, 10,0\% inferiores aos níveis recomendados pelo AFRC (1993).
\end{abstract}

Palavras-chave: novilhos, origem leiteira, composição corporal, exigências, proteína, energia

\section{Corporal Composition, Weight Gain Composition and Nutritional Requirements of Dairy Steers}

ABSTRACT - This work was conducted to study the net requirements of energy for maintenance and weight gain, the net requirements of protein for weight-gain and the dietetic requirements of protein and energy, as well as, the changes in corporal composition of dairy steers as live weight increased, with the purpose of meat production. Sixteen Holstein dairy steers with initial average age and weight of 20 months and $202.0 \mathrm{~kg}$ were used. The animals were divided into five groups: one group of animals was slaughtered at the beginning of the trial (AI), the other was submitted to restricted feeding (AR) and three groups were ad libitum fed (AL-1, AL-2 and AL-3) and they were slaughtered when the individual weights of 250.0, 300.0, and $350.0 \mathrm{~kg}$ were reached, respectively. The AR group received $15.0 \%$ above maintenance requirements levels of protein and energy. The diet contained 1:1 forage to concentrate ratio on dry matter basis with $12.48 \%$ of crude protein. The net requirement of energy for maintenance (NEm) was determined by regression of log heat production in function of metabolizable energy intake, as the heat production at zero level of energy intake. Regression equations of log body contens of protein, fat and energy in fucntion of the log of the empty body weight (EBW) were fitted, based on the data from AI, AL-1, AL2 and AL-3 steers, allowing to estimate body composition for any EBW, in the studied range. Equations to estimate composition of EBW gain were obtained by differentiation of regression equations. The estimated net energy requirement for maintenance of the steers were $68.44 \mathrm{kcal} /$ $\mathrm{kg} \cdot{ }^{75}$. The estimated net protein requirements for weight gain was similar to those values recomended by AFRC (1993). The estimated total metabolizable energy requirement was, nearly 10.0\% lower than recomended twose by AFRC (1993).

Key Words: dairy steers, body compositon, requirements, protein, energy

\section{Introdução}

Até o presente momento, os pesquisadores nacionais, na maioria das vezes, têm se dedicado prioritariamente ao estudo de composição corporal, ganho de peso e exigências nutricionais de animais provenientes de rebanhos de corte. Além disso, os estudos têm contemplado animais abatidos com pesos vivos entre 350,0 e $550,0 \mathrm{~kg}$ (PIRES et al., 1993a,b; LANA et al., 1992a,b; CASTILLO ESTRADA, 1996; e PAULINO, 1996). Há, portanto, carência de informações, no Brasil, quanto às exigên-

\footnotetext{
${ }^{1}$ Parte da Tese de doutorado do primeiro autor apresentada à UFV, parcialmente financiada pelo CNPq.

2 Doutor em Zootecnia, DZO/UFV, Viçosa, MG.

${ }^{3}$ Pesquisador Titular do LZNA, CCTA, UENF, Campos dos Goytacazes, RJ.
} 
cias nutricionais de animais de origem leiteira de menores pesos. Deve-se, ainda, salientar que animais submetidos à restrição nutricional na fase inicial de cria, como acontece normalmente com bezerros machos provenientes de rebanhos leiteiros, têm seu crescimento retardado, não apresentando geralmente ganho compensatório, podendo ter seu desenvolvimento permanentemente comprometido (RYAN, 1990).

O conhecimento das exigências nutricionais desses animais, bem como das variações de sua composição corporal, é necessário ao desenvolvimento de sistemas de produção que permitam sua exploração racional.

À medida que a idade do animal avança, aumenta o conteúdo de gordura e diminui o de proteína no corpo e no ganho de peso (LANA et al., 1992c). Animais de maturação precoce apresentam maior conteúdo de gordura e menor de proteína que os tardios, para o mesmo peso vivo.

WALDMAN et al. (1971) verificaram que, em novilhos holandeses, ração com alto nível de energia resultou em maior crescimento do tecido adiposo na carcaça, em relação aos músculos, enquanto nível médio de energia acarretou crescimento de tecido adiposo e muscular na mesma proporção. Entretanto, GARRETT (1980) afirma que a raça tem influência muito mais marcante sobre a composição corporal, para o mesmo peso vivo ou peso de carcaça, que o nível nutricional.

O decréscimo verificado no conteúdo corporal de proteína e o aumento no de gordura, com a elevação do peso do animal, são atribuídos à desaceleração do crescimento muscular, resultando em menor conteúdo de proteína por $\mathrm{kg}$ de ganho de peso corporal vazio (PCVZ), à medida que o peso do animal se eleva, concomitantemente com o maior acúmulo de tecido adiposo (BERG e BUTTERFIELD, 1976). O ARC (1980) estimou para animais castrados, de raças de porte médio, com PCVZ de 200,0 e 400,0 kg, conteúdos de proteína de 174 e $162 \mathrm{~g} / \mathrm{kg}$ de PCVZ; gordura, de 143,0 e 247,0 g/kg de PCVZ; e energia, de 2,32 e $3,23 \mathrm{Mcal} / \mathrm{kg}$ de PCVZ, respectivamente.

LANA et al. (1992c) estimaram ganhos de 229,2 e $288,1 \mathrm{~g}$ de gordura por $\mathrm{kg}$ de ganho de PCVZ e exigências, por $\mathrm{kg}$ de ganho de PCVZ, de 152,0 e 143,2 g de proteína e 3,38 e 3,31 mcal de energia, para animais mestiços Holandês x Gir, castrados, com 250,0 e 300,0 kg de PCVZ, respectivamente.

O ARC (1980) estima ganho de proteína por kg de ganho de PCVZ (exigências líquidas) de 162,0 e $151,0 \mathrm{~g}$ para animais não-castrados de raça de porte médio, com PCVZ de 200,0 e 400,0 kg, respectivamente.
Sob condições brasileiras, FONTES (1995) diferenciou os requerimentos líquidos de energia e proteína segundo a condição sexual (animais castrados e inteiros) e os grupos genéticos (animais zebuínos e mestiços Europeu x Zebu). Esse autor verificou que os requerimentos variaram de acordo com o sexo e grupo genético, com os animais castrados apresentando requerimentos de proteína inferiores aos dos inteiros, o que foi atribuído ao menor potencial para crescimento muscular dos primeiros.

Segundo o NRC (1984), a eficiência de utilização de energia metabolizável para mantença varia de 57,6 a $68,6 \%$, para concentrações de energia metabolizável da dieta de 2,0 a 3,2 Mcal/kg de matéria seca.

As exigências de proteína dos ruminantes são atendidas pelos aminoácidos absorvidos no intestino delgado, que são provenientes principalmente da proteína microbiana e da proteína dietética não-degradada no rúmen (PNDR). O AFRC (1993) introduziu o conceito de proteína metabolizável (PM) como a proteína verdadeira digestível total, disponível para o metabolismo, após a digestão do alimento e absorção dos aminoácidos pelo intestino delgado, metodologia também empregada pelo NRC (1996).

Os objetivos do presente trabalho foram estudar as exigências nutricionais para mantença e ganho de peso vivo de energia e proteína, bem como estudar as mudanças na composição corporal, com elevação do peso vivo, de animais holandeses e mestiços 7/8 e 15/16 Holandês $\mathrm{x}$ Zebu, submetidos a níveis nutricionais sub-ótimos, durante a fase de cria.

\section{Material e Métodos}

Este experimento foi realizado no período de 9 de novembro de 1992 a 29 de julho de 1993. Foram utilizados 16 novilhos machos, castrados, holandeses puros por cruza (HPC) e mestiços 7/8 e 15/16 Holandês $\mathrm{x}$ Zebu, com idade e peso vivo inicial médios de 20 meses e 202,0 kg, respectivamente, originários do rebanho pertencente ao Departamento de Zootecnia (DZO) da Universidade Federal de Viçosa. Durante a fase de cria, os animais haviam sido submetidos a aleitamento artificial, com desmama aos 56 dias de idade. Após a desmama, permaneceram em piquete provido de coberta, recebendo capim-napier picado e, até os 120 dias de idade, suplemento concentrado, na base de 1,0 kg por cabeça por dia. A partir dos 6 meses de idade, receberam, basicamente, pasto mais suplemento volumoso na seca.

No período seco anterior ao experimento, os 
animais permaneceram em piquete, recebendo silagem de capim-elefante (Pennisetum purpureum, Schum), suplemento mineral e, nos últimos trinta dias, suplemento concentrado. Antes do início do experimento, foram identificados com brincos numerados e tratados contra ecto e endoparasitas. Durante o experimento, os animais foram mantidos em regime de confinamento, em baias individuais de piso concretado, com área de $8 \mathrm{~m}^{2}$ por animal, em galpão de alvenaria coberto.

O período de adaptação às instalações teve duração de 12 dias, uma vez que os animais estavam adaptados a regime alimentar semelhante ao utilizado no experimento. Nesse período, todos os animais receberam a mesma ração ad libitum.

Após o período de adaptação, quatro novilhos foram abatidos (grupo AI), determinando-se sua composição corporal, em termos de gordura e proteína, peso corporal vazio (PCVZ), além da relação média entre seu PCVZ e o peso vivo, que foi utilizada para se estimar o PCVZ inicial dos animais remanescentes. Estes últimos foram divididos em quatro grupos de três animais cada, uniformes quanto ao peso vivo e à condição corporal, recebendo aleatoriamente os tratamentos:

AR: Ração em quantidades limitadas suprindo níveis de energia e proteína $15 \%$ acima aos de mantença:

AL-1: Ração ad libitum até o abate aos $250,0 \mathrm{~kg}$ de peso vivo;

AL-2: Ração ad libitum até o abate aos $300,0 \mathrm{~kg}$ de peso vivo;

AL-3: Ração ad libitum até o abate aos $350,0 \mathrm{~kg}$ de peso vivo.

A ração usada foi formulada segundo as normas do NRC (1984) para possibilitar aos animais AL-1, AL-2 e AL-3 ganho de peso diário de $1,0 \mathrm{~kg}$, atendendo, ao mesmo tempo, às exigências de proteína degradável no rúmen (PDR) e proteína não-degradável no rúmen (PNDR), segundo o ARC (1980). Os animais do lote AR receberam a mesma ração, em quantidades limitadas, de forma a ingerirem níveis de energia e proteína $15 \%$ acima das exigências de mantença.

A composição percentual da ração experimental e os conteúdos de energia metabolizável, proteína bruta e macroelementos minerais na matéria seca da silagem, do concentrado e da ração são apresentados nas Tabelas 1 e 2, respectivamente.

Para os lotes que receberam ração ad libitum, a quantidade oferecida foi ajustada de forma a se manterem sobras entre 5 e $10 \%$ da oferta. As quantida-
Tabela 1 - Composição percentual da ração experimental (base da MS)

Table 1 - Percentage composition of the experimental ration (DM basis)

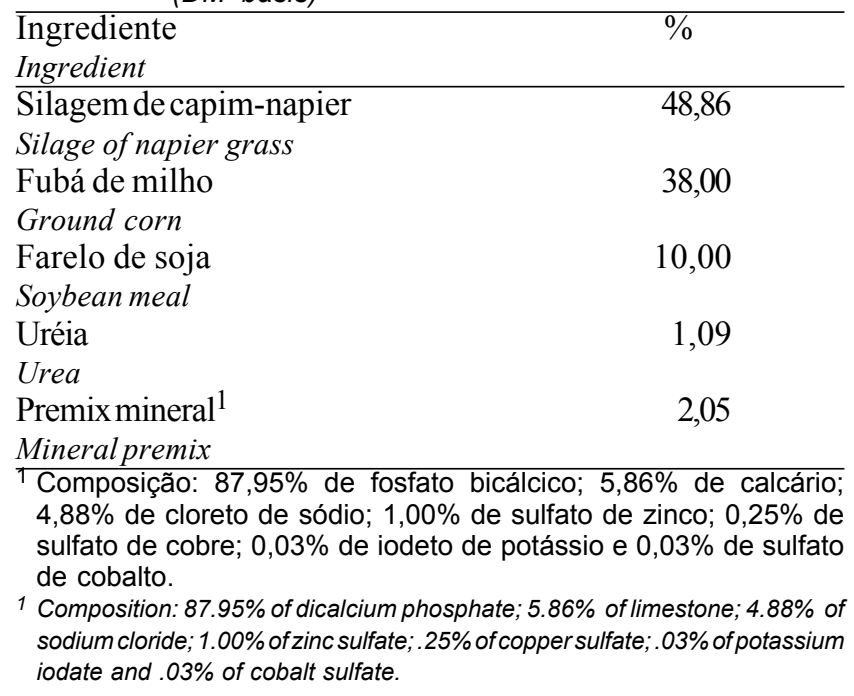

des de ração fornecida e sobras foram registradas, diariamente, e amostras da ração e individuais das sobras foram coletadas, semanalmente, congeladas e armazenadas a $-15^{\circ} \mathrm{C}$ para análises químicas posteriores.

As amostras semanais de ração e sobras individuais foram agrupadas em amostras compostas mensais, de forma proporcional, sendo submetidas à présecagem em estufa de ventilação forçada à temperatura de $50-60^{\circ} \mathrm{C}$, durante 72 horas. Em seguida, foram moídas em moinho tipo "Willey", com peneira de 30 mesh e acondicionadas em vidros para análises químicas posteriores.

O período experimental não teve duração préestabelecida. Os animais foram abatidos assim que atingiram os pesos pré-estabelecidos de 250,0;300,0; e $350,0 \mathrm{~kg}$, correspondentes aos tratamentos AL-1, AL-2 e AL-3, respectivamente. Periodicamente, os animais foram pesados de forma que cada animal pudesse ser abatido o mais próximo possível do peso pré-estabelecido. À medida em que era abatido um animal do lote AL-1, abatia-se também o animal do lote $\mathrm{AR}$, mais semelhante a ele, quanto ao peso e à condição corporal ao início do experimento.

Com o objetivo de se determinar a digestibilidade da energia bruta da ração experimental, foram realizados dois ensaios empregando-se os animais dos grupos recebendo alimentação ad libitum, nas baias individuais, já convenientemente adaptados à ração. Em cada ensaio o período de coleta teve duração de sete dias, durante os quais se procedeu à amostragem da ração fornecida, das sobras e das fezes. Esta 
162 Rev. bras. zootec.

Tabela 2 - Teores de matéria seca (MS), proteína bruta (PB), energia metabolizável (EM), cálcio (Ca), fósforo (P), magnésio $(\mathrm{Mg})$, sódio $(\mathrm{Na})$ e potássio $(\mathrm{K})$ dos ingredientes e da ração experimental (base da $\mathrm{MS})^{1}$

Table 2- $\quad$ Contents of dry mater (DM), crude protein (CP), metabolizable energy (ME), calcium (Ca), phosphorus (P), magnesium (Mg), sodium ( $\mathrm{Na}$ ) and potassium $(\mathrm{K})$ of the ingredients and of the experimental diet (DM basis) ${ }^{1}$

\begin{tabular}{|c|c|c|c|c|c|c|c|c|}
\hline $\begin{array}{l}\text { Ingrediente } \\
\text { Ingredient }\end{array}$ & $\begin{array}{c}\text { MS (\%) } \\
D M\end{array}$ & $\begin{array}{c}\mathrm{PB}(\%) \\
C P\end{array}$ & $\begin{array}{l}\mathrm{EM}^{2} \\
M E\end{array}$ & $\mathrm{Ca}(\%)$ & $\mathrm{P}(\%)$ & $\operatorname{Mg}(\%)$ & $\mathrm{Na}(\%)$ & $\mathrm{K}(\%)$ \\
\hline Silagem & 45,00 & 3,14 & - & 0,28 & 0,10 & 0,39 & 0,02 & 0,53 \\
\hline $\begin{array}{l}\text { Silage } \\
\text { Concentrado }\end{array}$ & 87,94 & 19,86 & - & 0,95 & 0,85 & 0,13 & 0,14 & 0,68 \\
\hline $\begin{array}{l}\text { Concentrate } \\
\text { Ração total }\end{array}$ & - & 12,48 & 1,88 & 0,63 & 0,49 & 0,24 & 0,08 & 0,53 \\
\hline
\end{tabular}

${ }_{1}^{1}$ Análises realizadas no Laboratório de Nutrição Animal do Departamento de Zootecnia da UFV.

$2 \mathrm{Mcal}$ de EM/kg de MS.

3 Valores estimados a partir da composição da silagem e dos ingredientes do concentrado.

1 Analyses performed at Animal Nutrition Lab of Animal Science of UFV.

${ }^{2} \mathrm{Mcal}$ of ME/kg of DM.

${ }^{3}$ Values estimated from composition of silage and of components of the concentrate.

últimas foram coletadas diretamente do reto dos animais. As amostras foram homogeneizadas, acondicionadas em sacos plásticos e armazenadas a $-15^{\circ} \mathrm{C}$ para análises químicas posteriores.

Durante os períodos de coleta, os animais receberam quantidades de ração $5 \%$ acima do consumo médio individual verificado nos 12 dias que antecederam a cada período de coleta.

$\mathrm{Na}$ determinação da digestibilidade aparente da energia bruta da ração, utilizou-se o indicador interno cinza insolúvel em ácido (CIA) para se estimar a produção de matéria seca fecal (MSF), utilizando a metodologia proposta por VAN KEULEN e YOUNG (1977), segundo a fórmula:

$\mathrm{kg}$ de MS fecal estimada $=\mathrm{kg}$ de indicador ingerido $\mathrm{x} 100$ $\%$ do indicador nas fezes

$\mathrm{Na}$ conversão de energia digestível em metabolizável, utilizou-se o fator 0,82 , proposto pelo AFRC (1991).

Ao atingirem os pesos individuais pré-estabelecidos, os animais foram abatidos após jejum de 16 horas. $\mathrm{Na}$ ocasião, foram pesados e amostrados o rúmen-retículo, omaso, abomaso e os intestinos delgado e grosso, após serem esvaziados e lavados, obtendo-se, ainda, os pesos e as amostras de sangue, couro, pés, cabeça, cauda, órgãos e carcaça.

Os pesos das vísceras foram somados aos pesos dos demais componentes do corpo, obtendo-se o peso corporal vazio (PCVZ) de cada animal.

As duas meias-carcaças foram pesadas no dia do abate e, posteriormente, armazenadas em câmara fria a $-5^{\circ} \mathrm{C}$, durante período de 18 horas, após o qual foram novamente pesadas e processadas.

$\mathrm{Na}$ meia-carcaça esquerda foi obtida a seção da $9^{\mathrm{a}}$ a $11^{\mathrm{a}}$ costela (seção $\mathrm{HH}$ ), segundo HANKINS e HOWE (1946), a qual foi dissecada, separando-se os tecidos muscular, adiposo e ósseo, que foram pesados. Estes tecidos foram amostrados, moídos e armazenados em sacos plásticos a $-15^{\circ} \mathrm{C}$ para análises químicas posteriores.

As proporções de músculo, gordura e ossos da carcaça foram estimadas, com base nas proporções destes componentes na seção HH, por intermédio das equações propostas por HANKINS e HOWE (1946), descritas abaixo:

$\%$ de músculo $=16,08+0,80 \mathrm{X}$

$\%$ de tecido adiposo $=3,54+0,80 \mathrm{X}$; e

$\%$ de ossos $=5,52+0,57 \mathrm{X}$.

em que

X é a proporção do componente na seção $\mathrm{HH}$.

As amostras de vísceras, órgãos, couro, cauda, cabeça, pés e as provenientes das seções HH foram acondicionadas em vidros com capacidade de, aproximadamente, $250 \mathrm{~mL}$ e levadas à estufa a $105^{\circ} \mathrm{C}$, por períodos de 48 a 72 horas, para a determinação da matéria seca gordurosa (MSG), sendo utilizadas as seguintes quantidades de amostras para as diferentes partes do corpo: músculo (120 g), tecido adiposo, vísceras e órgãos (200 g), ossos, cauda e couro, cabeça e pés $(100 \mathrm{~g})$.

Após secas e pesadas, as amostras foram reaquecidas e desengorduradas por meio de lavagens sucessivas com éter de petróleo, segundo procedimento descrito por KOCK e PRESTON (1979), obtendo-se a matéria seca pré-desengordurada (MSD). Em seguida, estas amostras foram moídas em moinho de bola e mantidas à temperatura de $-15^{\circ} \mathrm{C}$ para análises químicas posteriores.

As amostras de sangue (400 g) foram pré-secas em estufa de ventilação forçada à temperatura de 55 a $60^{\circ} \mathrm{C}$ 
por 48 horas, sendo, a seguir, moídas em moinho de bola, sem sofrerem o processo de pré-desengorduramento.

As análises químicas e bromatológicas de todas as amostras foram efetuadas no Laboratório de $\mathrm{Nu}$ trição Animal do Departamento de Zootecnia da Universidade Federal de Viçosa, conforme metodologias descritas por SILVA (1990).

Os conteúdos de proteína e gordura das carcaças foram estimados a partir de suas concentrações nos músculos, no tecido adiposo e nos ossos da seção HH e das proporções desses tecidos na carcaça, estimadas por intermédio das equações de HANKINS e HOWE (1946), descritas anteriormente.

A composição química corporal foi determinada considerando-se o peso de cada parte do corpo (carcaça, couro, órgãos, vísceras, sangue, cabeça, entre outros) e suas respectivas composições químicas.

O conteúdo corporal de energia foi calculado utilizando-se os equivalentes calóricos da proteína e gordura e suas proporções no corpo, segundo o ARC (1980), por intermédio da seguinte equação:

Energia corporal $(\mathrm{Mcal})=(5,6405 \mathrm{X})+(9,3929 \mathrm{Y})$, em que

$\mathrm{X}=$ proteína corporal $(\mathrm{kg})$ e

$\mathrm{Y}=$ gordura corporal $(\mathrm{kg})$.

Para a determinação da quantidade de energia retida no corpo dos animais, utilizou-se a técnica do abate comparativo. As concentrações de energia no corpo dos animais referência (AB), abatidos ao início do experimento, foram consideradas representativas dos demais animais dos vários tratamentos.

Para a conversão do PV em PCVZ, dentro do intervalo de pesos incluído no estudo, utilizou-se a equação obtida por regressão do PCVZ dos 16 animais utilizados no experimento, em função do peso vivo.

Para a conversão das exigências para ganho de PCVZ em exigências para ganho de PV, utilizou-se o fator 1,12 obtido neste experimento.

As exigências de energia líquida para mantença (Elm) foram determinadas por meio da regressão do logaritmo da produção de calor, em função do consumo de energia metabolizável (EM), ambos em $\mathrm{kcal} / \mathrm{kg}^{0,75}$ / dia, extrapolando-se a equação para o nível zero de consumo deEM, segundo a metodologia de LOFGREEN e GARRETT (1968), utilizando-se nos cálculos os animais dos tratamentos AR, AL-1, AL-2 e AL-3.

Para se estimarem os conteúdos de proteína, gordura e energia retidos no corpo de animais com pesos dentro da faixa estudada, foram ajustadas equações de regressão do logaritmo de seus conteúdos corporais $(\mathrm{kg})$, em função do logaritmo do peso corporal vazio (ARC, 1980), conforme o modelo:

em que

$$
\mathrm{Y}_{\mathrm{ij}}=\mu+\mathrm{b}_{1} \mathrm{X}_{1 \mathrm{i}}+\mathrm{e}_{\mathrm{ij}} \text {, }
$$

$\mathrm{Y}_{\mathrm{ij}}=$ logaritmo do conteúdo total de proteína $(\mathrm{kg})$, gordura $(\mathrm{kg})$ e energia (Mcal) retido no corpo vazio;

$\mu=$ efeito da média (Intercepto);

$\mathrm{b}_{1}=$ coeficiente de regressão do logaritmo do conteúdo de proteína, gordura ou energia, em função do logaritmo do peso corporal vazio;

$\mathrm{X}_{1 \mathrm{i}}=$ logaritmo do peso corporal vazio; e

$\mathrm{e}_{\mathrm{ij}}=$ erro aleatório, pressuposto normalmente distribuído, com média igual a zero e variância $\sigma^{2}$.

As análises de regressão foram avaliadas, quanto ao coeficiente de determinação segundo STELL e TORRIE (1960), por intermédio do programa LSMLMW (Least Squares and Maximum Likelihood Mixed Model), versão PC-1, HARVEY (1990).

Os acréscimos de proteína e energia (exigências líquidas) e gordura, por $\mathrm{kg}$ de ganho de peso corporal vazio (GPCVZ), foram determinados por derivação das equações de regressão correspondentes, anteriormente citadas, obtendo-se equações do tipo:

$$
\mathrm{Y}^{\prime}=\mathrm{b} \cdot 10^{\mathrm{a}} \cdot \mathrm{X}^{(\mathrm{b}-1)} \text {, }
$$

em que

$\mathrm{Y}^{\prime}=$ conteúdo de proteína, gordura e energia por $\mathrm{kg}$ de GPCVZ;

$\mathrm{b}=$ coeficiente de regressão do logaritmo do conteúdo de proteína, gordura e energia, em função do logaritmo do PCVZ;

$\mathrm{a}=$ intercepto da equação de regressão;

$\mathrm{X}=\mathrm{PCVZ}(\mathrm{kg})$.

As exigências líquidas de proteína e energia para ganho de peso vivo foram obtidas dividindo-se as respectivas exigências de ganho de $\mathrm{PCVZ}$ pelo fator 1,12, obtido nas condições deste experimento.

As estimativas das exigências de proteína e energia foram calculadas para animais na faixa de peso de 150,0 a $350,0 \mathrm{~kg}$ de peso vivo e ganho de peso diário de $1,0 \mathrm{~kg}$.

As exigências de energia metabolizável (EM) foram determinadas utilizando-se a equação abaixo, segundo o AFRC (1993):

$$
\mathrm{EM}=(\mathrm{ELm} / \mathrm{K}) \times \ln (\mathrm{B} / \mathrm{B}-\mathrm{R}-1),
$$

em que

ELm= energia líquida de mantença, determinada neste estudo;

$\mathrm{K}=\mathrm{Km} \times \ln (\mathrm{Km} / \mathrm{Kf})$;

$\mathrm{Km}=0,35 \mathrm{qm}+0,503$;

$\mathrm{Kf}=0,78 \mathrm{qm}+0,006$;

$\mathrm{qm}=\mathrm{M} / 18,8$;

$\mathrm{M}=\mathrm{MJ}$ de $\mathrm{EM} / \mathrm{kg}$ de $\mathrm{MS}$ da ração, utilizando-se o valor de 7,88 MJ (1,88 Mcal) de EM por kg de MS, 
determinado neste estudo;

$\mathrm{B}=\mathrm{Km} /(\mathrm{Km}-\mathrm{Kf})$; e

$\mathrm{R}=\mathrm{ELg} / \mathrm{Elm}$, determinada neste estudo, em que: $\mathrm{ELg}=$ energia líquida para ganho e ELm= energia líquida para mantença.

A exigência de energia digestível foi estimada a partir da exigência de energia metabolizável, considerando-se ED igual a EM/0,82.

A exigência de proteína metabolizável foi estimada, de acordo com a metodologia do AFRC (1993), pela soma da proteína metabolizável de mantença e proteína líquida de ganho, considerando-se 0,59 como o fator de eficiência de retenção de proteína para ganho, descrito a seguir.

PMmp $=2,3 \times$ PV $^{0,75}+$ PLg/0,59,

sendo a PLg determinada neste estudo.

\section{Resultados e Discussão}

Por regressão do logaritmo da produção de calor (PC), em função do consumo de energia metabolizável (EM), ambos em kcal por unidade de tamanho metabólico, por dia, obteve-se a equação abaixo:

$\log P C=1,8220512+0,00194008 \times C E M, R^{2}=0,97$

De acordo com a metodologia proposta por LOFGREEN e GARRETT (1968), extrapolando-se a produção de calor para o nível zero de consumo de energia metabolizável (CEM), obtém-se o valor de $68,44 \mathrm{kcal} / \mathrm{kg}^{0,75} / \mathrm{dia}$, como exigência de energia líquida para mantença (ELm), para animais em crescimento de origem leiteira.

Os valores encontrados neste experimento são 12,67; 11,78; e 18,18\% superiores aos de GONÇALVES (1988), PAULINO (1996) e SALVADOR (1980), que encontraram valores de 59,8; 60,38 e 56,0 $\mathrm{kcal} / \mathrm{kg}^{0,75} / \mathrm{dia}$, respectivamente, para bovinos de raças zebuínas. Contudo, foram $11,12 \%$ inferiores ao valor obtido por LOFGREEN e GARRETT (1968), de $77,0 \mathrm{kcal} / \mathrm{kg}^{0,75} / \mathrm{dia}$, para bovinos europeus.

BOIN (1995), trabalhando com bovinos zebuínos, obteve valores que variaram de 69,8 a $79,8 \mathrm{kcal} /$ $\mathrm{kgPCVZ}^{0,75} /$ dia como exigência de energia líquida para mantença.

Os resultados deste trabalho, com animais Holandeses, foram, em geral, mais elevados que os de outros autores que utilizaram, no Brasil, a mesma metodologia, trabalhando com animais zebuínos e mestiços Europeu x Zebu, o que está de acordo com as constatações de ROGERSON (1971), que observou menor produção média de calor de jejum para bovinos zebuínos em relação aos taurinos. $\mathrm{O}$
National Research Council (1996) considera que os requerimentos de energia de mantença do Bos indicus são inferiores aos do Bos taurus.

Abordando as menores exigências de energia para mantença em zebuínos, em relação a bovinos de raças européias, JORGE (1997) atribuiu a diferença, em parte, ao menor tamanho de órgãos internos nos animais zebuínos, em relação a europeus e mestiços Europeu x Zebu. Acrescido a esse fato, PERON et al. (1993) observaram que os zebuínos apresentam, em relação aos taurinos, menor proporção da gordura nos depósitos internos, que são metabolicamente mais ativos que a gordura externa, o que contribuiria para suas menores exigências de energia para mantença.

As exigências líquidas de energia para mantença (ELm), expressas em Mcal/animal/dia, para a faixa de peso vivo variando de 150,0 a $300,0 \mathrm{~kg}$, são mostradas na Tabela 3.

Os valores obtidos neste experimento, para um animal de 300,0 kg de PV, são aproximadamente $13,7 \%$ inferiores aos preconizados pelo NAS (1984) (5,5 Mcal/dia) para animal de raça grande, ao usar a recomendação de $77,0 \mathrm{kcal} / \mathrm{kg}^{0,75}$ de LOFGREEN e GARRETT (1968). Por outro lado, são próximos aos de PIRES et al. (1993b), que trabalhando com bovinos cruzados Nelore x Limousine, com 400,0 kg de PV, encontraram valores de 4,42 Mcal/animal/dia, para exigência de energia líquida para mantença (ELm).

Os valores encontrados neste experimento, para animais de 300,0 kg de PV, são 9,19\% superiores aos propostos por PAULINO (1996), para animais inteiros de origem zebuína.

Os parâmetros das equações de regressão do logaritmo dos conteúdos de proteína, gordura e ener-

Tabela 3 - Exigências líquidas de energia para mantença (ELm), em Mcal/animal/dia, em função do peso vivo (PV) ou peso corporal vazio (PVCZ), para novilhos de origem leiteira

Table 3 - Net requirements of energy for maintenance (NEm) in Mcal/animal/day, according to the live weight $(L W)$ or empty body weight (EBW), for dairy steers

\begin{tabular}{lcc} 
& empty body weight $(E B W)$, for dairy steers \\
\hline PV $(\mathrm{kg})$ & PCVZ & ELm(Mcal/animal/dia) \\
$L W$ & $E B W$ & NEm (Mcal/animal/day) \\
\hline 150,0 & 112,9 & 2,85 \\
175,0 & 135,2 & 3,19 \\
200,0 & 157,5 & 3,53 \\
225,0 & 179,7 & 3,86 \\
250,0 & 202,0 & 4,17 \\
275,0 & 224,3 & 4,48 \\
300,0 & 246,6 & 4,79 \\
350,0 & 291,2 & 5,37 \\
\hline
\end{tabular}


gia, em função do logaritmo do PCVZ, que foram utilizados para se estimarem seus conteúdos no corpo, são mostrados na Tabela 4.

Os coeficientes de determinação das equações $\left(\mathrm{R}^{2}\right)$ variaram de 0,91 a 0,99 , mostrando bom ajustamento das equações aos dados experimentais. Estes valores foram semelhantes aos observados por LANA et al. (1992b,c) e PIRES et al. (1993a,b), que utilizaram a mesma metodologia e trabalharam com animais Nelore e mestiços Europeu x Zebu.

Os conteúdos corporais totais de proteína (PT) e gordura (GT), bem como os conteúdos de proteína, gordura e energia por $\mathrm{kg}$ de PCVZ, estimados por intermédio das equações de regressão supracitadas, para animais com pesos vivos variando de 150,0 e $300,0 \mathrm{~kg}$, são apresentados na Tabela 5 .

Observa-se que os conteúdos totais de proteína e gordura aumentaram à medida que o peso vivo se elevou. Por outro lado, em termos de concentrações (g/kg de PCVZ ou Mcal $/ \mathrm{kg}$ de PCVZ), houve decréscimo no conteúdo corporal de proteína e aumento no de gordura, assim como no conteúdo de energia, com o aumento do peso vivo dos animais. As mesmas tendências ficam claras nos resultados de TEIXEIRA (1984), GONÇALVES (1988), LANA et al. (1992b,c), PIRES et al. (1993 a,b) e FREITAS (1995), que trabalharam com animais de origem zebuína, abatidos com pesos vivos variando de 400,0 a $550,0 \mathrm{~kg}$.

Os conteúdos corporais de gordura e energia verificados no presente trabalho são semelhantes e os de proteína pouco inferiores aos observados por LANA et al. (1992b,c) em animais castrados Nelore e mestiços Europeu x Zebu.

FONTES (1995), ao analisar em conjunto dados de diferentes experimentos, obtidos por meio de metodologia semelhante, encontrou mudanças nas proporções de proteína de 197,0 para $167,0 \mathrm{~g} / \mathrm{kg}$ de PCVZ; gordura, de 124,0 para $259,0 \mathrm{~g} / \mathrm{kg}$ de PCVZ; e energia, de 2,29 para 3,34 $\mathrm{Mcal} / \mathrm{kg}$ de PCVZ, quando o PCVZ se elevou de 300,0 para $450,0 \mathrm{~kg}$, em animais mestiços Holandês x Nelore, castrados.

Pode-se observar que a relação G/P se elevou

Tabela 4 - Parâmetros das equações de regressão do logaritmo do conteúdo corporal de proteína (kg), gordura (kg) e energia (Mcal) no corpo vazio, em função do logaritmo do peso corporal vazio (PCVZ), dos novilhos

Table 4- Parameters of the regression equations of log body content of protein ( $\mathrm{kg})$, fat ( $\mathrm{kg}$ ) and energy (Mcal) in the empty body, in function of log empty body weight of the steers

\begin{tabular}{lccc}
\hline $\begin{array}{l}\text { Peso corporal vazio }(\mathrm{kg}) \\
\text { Empty body weight }\end{array}$ & $\begin{array}{c}\text { Parâmetro } \\
\text { Parameter }\end{array}$ & $\mathrm{R}^{2}$ \\
\cline { 2 - 3 } & $\begin{array}{c}\text { Intercepto } \\
\text { Intercept }\end{array}$ & $\begin{array}{c}\text { Coeficiente de regressão } \\
\text { Regressioncoefficient }\end{array}$ & 0,94385687 \\
\hline $\begin{array}{l}\text { Proteína } \\
\text { Protein }\end{array}$ & $-0,6184553$ & 1,34514366 & 0,99 \\
Gat & $-1,6617793$ & 1,17407016 & 0,91 \\
Energia & $-0,0401712$ & & 0,96 \\
Energy & & \\
\hline
\end{tabular}

Tabela 5 - Conteúdos corporais totais de proteína (PBT, $\mathrm{kg}$ ) e gordura (GT, kg), conteúdos de proteína (g), gordura (g) e energia (Mcal) por kg de peso de corpo vazio (PCVZ) e relação entre conteúdos de gordura e proteína (G/P) para novilhos de origem leiteira, em função do peso vivo (PV) ou peso de corpo vazio (PCVZ)

Table 5 - Total body content of protein (TBCP, $\mathrm{kg}$ ) and fat (TF, $\mathrm{kg}$ ) and protein $(\mathrm{g})$, fat $(\mathrm{g})$ and energy (Mcal) content per $\mathrm{kg}$ of empty body weight $(E B W)$ and ratio between contents of fat and protein $(F / C P)$, for dairy steers, according to the live weight (LW) or empty body weight (EBW)

\begin{tabular}{|c|c|c|c|c|c|c|c|}
\hline \multirow[t]{3}{*}{$\begin{array}{l}\mathrm{PV}(\mathrm{kg}) \\
L W\end{array}$} & \multirow[t]{3}{*}{$\begin{array}{c}\mathrm{PCVZ}(\mathrm{kg}) \\
E B W\end{array}$} & \multirow[t]{3}{*}{$\begin{array}{c}\text { PBT }(\mathrm{kg}) \\
T C P\end{array}$} & \multirow[t]{3}{*}{$\begin{array}{c}\mathrm{GT}(\mathrm{kg}) \\
T F\end{array}$} & \multicolumn{3}{|c|}{$\begin{array}{l}\text { Conteúdo por kg de PCVZ } \\
\text { Content per } \mathrm{kg} \text { of } E B W\end{array}$} & \multirow[t]{3}{*}{$\begin{array}{l}\text { Relação G/P } \\
\text { Relation } F / P\end{array}$} \\
\hline & & & & Proteína (g) & Gordura (g) & Energia(Mcal) & \\
\hline & & & & Protein & Fat & Energy & \\
\hline 150,0 & 112,9 & 20,84 & 12,57 & 184,6 & 111,3 & 2,08 & 0,603 \\
\hline 175,0 & 135,2 & 24,70 & 16,01 & 182,8 & 118,5 & 2,14 & 0,648 \\
\hline 200,0 & 157,5 & 28,53 & 19,67 & 181,2 & 124,9 & 2,20 & 0,689 \\
\hline 225,0 & 179,7 & 32,33 & 23,50 & 179,9 & 130,7 & 2,25 & 0,727 \\
\hline 250,0 & 202,0 & 36,11 & 27,50 & 178,7 & 136,1 & 2,30 & 0,761 \\
\hline 275,0 & 224,3 & 39,85 & 31,66 & 177,6 & 141,1 & 2,34 & 0,794 \\
\hline 300,0 & 246,6 & 43,58 & 35,97 & 176,7 & 145,8 & 2,38 & 0,825 \\
\hline 350,0 & 291,2 & 50,98 & 44,98 & 175,06 & 154,4 & 2,45 & 0,882 \\
\hline
\end{tabular}


166 Rev. bras. zootec.

com o aumento dos pesos vivos dos animais. Esse comportamento está de acordo com as observações de Grant e Helferich, citados por PAULINO (1996), indicando as mudanças na composição dos tecidos acumulados, com o aumento do peso do animal, refletindo desaceleração do crescimento muscular e elevação da taxa de desenvolvimento do tecido adiposo.

Ao derivar as equações de regressão dos logaritmos dos conteúdos corporais de proteína, gordura e energia, em função do logaritmo do PCVZ, foram obtidas as equações de predição dos conteúdos de proteína, gordura e energia por kg de ganho de PCVZ (Tabela 6). Para proteína e energia, estes conteúdos correspondem às exigências líquidas para ganho de $1,0 \mathrm{~kg}$ de PCVZ.

As exigências líquidas de proteína e energia e os conteúdos de gordura por $\mathrm{kg}$ de ganho de PCVZ e a relação G/P no ganho, para novilhos com pesos vivos variando de 150,0 a 300,0 kg, encontram-se na Tabela 7 .

Houve decréscimo no acúmulo de proteína e aumento no de gordura, por unidade de ganho, à medida que os pesos dos animais se elevaram. Como o conteúdo energético do peso ganho é altamente influenciado pela proporção de gordura nos tecidos ganhos, observa-se aumento no valor energético, com o aumento do peso vivo dos animais. Estes resultados são concordantes com os obtidos por LANA et al. (1992b,c), PIRES et al. (1993a,b), FREITAS (1995), FONTES (1995), PAULINO (1996) e CASTILLO ESTRADA (1996).

Os acréscimos de gordura e energia, por $\mathrm{kg}$ de ganho, estimados no presente trabalho, para um animal de $300,0 \mathrm{~kg}$ de $\mathrm{PV}$, foram inferiores (31,93 e 26,77\%, respectivamente) e os de proteína, superiores $(14,17 \%)$ aos estimados por LANA et al. (1992c) para animais mestiços Holandês x Gir, castrados, de mesmo peso.

Em relação aos valores calculados por FONTES (1995), para animais mestiços Holandês $\mathrm{x}$ Nelore, ao analisar em conjunto dados obtidos em diferentes experimentos conduzidos no Brasil, os obtidos neste trabalho referentes a animais com $300,0 \mathrm{~kg}$ de PV foram 29,41\% superiores para proteína e 22,28 e $24,35 \%$ inferiores para gordura e energia, respectivamente.

As maiores exigências, por $\mathrm{kg}$ de ganho, de proteína e menores de energia, no presente estudo estariam, provavelmente, relacionadas à menor idade dos animais.

Já em relação aos resultados obtidos por PAULINO (1996), que trabalhou com animais inteiros de raças zebuínas, a exigência líquida de energia para ganho de $1,0 \mathrm{~kg}$ de $\mathrm{PCVZ}$, para um animal de $300,0 \mathrm{~kg}$ de PV, é 3,13\% inferior.

Tabela 6 - Equações de predição do ganho de proteína (g), gordura (g) e energia (Mcal) por kg de ganho de peso de corpo vazio (PCVZ), em função do PCVZ, em kg, para novilhos de origem leiteira

Table 6 - Prediction equations of the gain of protein $(g)$, fat $(g)$ and energy (Mcal) per kg of empty body weight (EBW) gain in function of the EBW in $\mathrm{kg}$, for dairy steers

Componente corporal Equação de predição

Bodycomponent Prediction equation

Proteína $\quad \mathrm{Y}^{\prime}=0,227222 \times \mathrm{PCVZ}^{-0,056143}$

Protein

Gordura $\quad \mathrm{Y}^{\prime}=0,029308 \times \mathrm{PCVZ}^{0,345144}$

Fat

Energia

$\mathrm{Y}^{\prime}=1,070343 \times \mathrm{PCVZ}^{0,174071}$

Energy

Tabela 7 - Ganhos de proteína (g), gordura (g) e energia (Mcal) por kg de peso de corpo vazio (PCVZ) ganho e relação entre ganho de gordura e proteína (G/P) em função do peso vivo (PV) ou peso de corpo vazio (PCVZ)

Table 7- Accretion of protein ( $g$ ), fat $(g)$ and energy (Mcal) per $\mathrm{kg}$ of empty body weight (EBW) gain and ratio between fat and protein accretion (F/P) according to live weight (LW) or empty body weight (EBW)

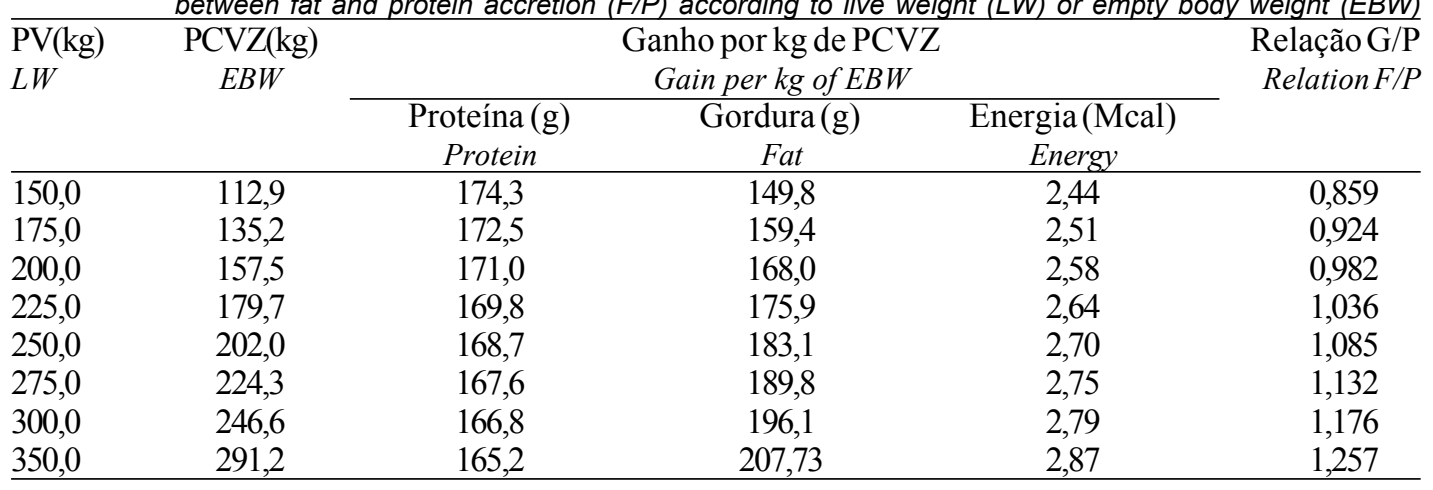


As estimativas de exigências líquidas de proteína e energia para ganho de $1,0 \mathrm{~kg}$ de PV encontram-se na Tabela 8.

Adotando-se a metodologia do AFRC (1993), foram obtidas as estimativas de exigências líquidas de proteína para mantença (PLm), que foram somadas às exigências líquidas de proteína para ganho de peso (PLg) obtidas no presente trabalho, chegandose às exigências de proteína metabolizável (PM) para atender aos requerimentos em nível de tecido (Tabela 9). As estimativas obtidas guardam estreita relação com as publicadas pelo AFRC (1993) para animais de origem leiteira, castrados e de porte médio, sendo $2,13 \%$ superiores e apenas $0,97 \%$ inferiores às encontradas por PAULINO (1996), que utilizou metodologia semelhante e trabalhou com animais zebuínos não-castrados.

As estimativas de exigências líquidas totais de energia e as exigências dietéticas, em termos de energia metabolizável(EM) e energia digestível(ED), encontram-se na Tabela 10.

Os requerimentos de energia líquida total obtidos neste experimento, para um animal de 300,0 kg de PV, foram 5,82\% inferiores aos encontrados por PAULINO (1996), para animais zebuínos não-castrados.

As exigências de energia metabolizável para um animal de $300,0 \mathrm{~kg}$ de PV foram 10,4\% inferiores às recomendações do AFRC (1993). Deve-se salientar que, nos cálculos realizados no presente estudo, utilizaram-se valores de exigências de energia líquida para mantença (ELm) e ganho, determinados experimentalmente.
Tabela 8 - Exigências líquidas de proteína e energia por kg de ganho de peso vivo, em função do peso vivo (PV) ou peso corporal vazio (PCVZ), para novilhos de origem leiteira

Table 8 - Net requirements of protein and energy per $\mathrm{kg}$ of live weight gain, according to the live weight ( $L W)$ or empty body weight (EBW), for dairy steers

\begin{tabular}{lccc}
\hline PV(kg) & PCVZ(kg) & $\begin{array}{c}\text { Proteína }(\mathrm{g}) \\
\text { Protein }\end{array}$ & $\begin{array}{c}\text { Energia(Mcal) } \\
\text { Energy }\end{array}$ \\
\hline 150,0 & $E B W$ & 155,4 & 2,17 \\
175,0 & 112,9 & 153,8 & 2,24 \\
200,0 & 135,2 & 152,5 & 2,30 \\
225,0 & 157,5 & 151,4 & 2,36 \\
250,0 & 179,7 & 150,4 & 2,40 \\
275,0 & 202,0 & 149,5 & 2,45 \\
300,0 & 224,3 & 148,7 & 2,49 \\
350,0 & 246,6 & 147,4 & 2,56 \\
\hline
\end{tabular}

Tabela 9 - Exigências líquidas de proteína para mantença (PLm), para ganho de peso (PLg) e de proteína metabolizável (PM), em g/dia, em função do peso vivo (PV) ou peso corporal vazio (PCVZ), para novilhos de origem leiteira

Table 9 - Net requirements of protein for maintenance (NPm), weight gain (NPg) and metabolizable protein (MP), in g/day, according to the live weight (LW) or empty body weight (EBW), for dairy steers

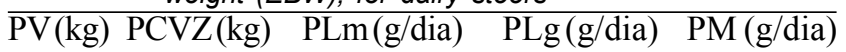

\begin{tabular}{lllll}
$L W$ & $E B W$ & $N P m(g / d a y)$ & $N P g(g / d a y)$ & $M P(g / d a y)$ \\
\hline
\end{tabular}

\begin{tabular}{lllll}
\hline 150,0 & 112,9 & 98,6 & 155,4 & 362,0 \\
175,0 & 135,2 & 110,7 & 153,8 & 371,4 \\
200,0 & 137,5 & 122,3 & 152,5 & 380,9 \\
225,0 & 179,7 & 133,6 & 151,4 & 390,2 \\
250,0 & 202,0 & 144,6 & 150,4 & 399,5 \\
275,0 & 224,3 & 155,3 & 149,5 & 408,8 \\
300,0 & 246,6 & 165,8 & 148,7 & 417,9 \\
350,0 & 291,2 & 186,1 & 147,4 & 435,9 \\
\hline
\end{tabular}

Tabela 10 - Exigências líquidas de energia para mantença (ELm), para ganho de peso (ELg) e energia líquida total (ELt) e exigências de energia metabolizável (EM) e de energia digestível (ED), em Mcal/animal/dia, em função do peso vivo (PV) ou do peso corporal vazio (PCVZ), para novilhos de origem leiteira

Table 10 - Net requirements of energy for maintenance (NEm), weight gain (NEg), total net energy requirements (NEt) and requirements of metabolizable (ME) and of digestible energy (DE), in Mcal/animal/day, according to the live weight ( $L W$ ) and empty body weight (EBW) of dairy steers

\begin{tabular}{lcccccc}
\hline PV(kg) & $\begin{array}{c}\text { PCVZ(kg) } \\
L W W\end{array}$ & ELm & ELg & Elt & EM & ED \\
& $E B W$ & $N E g$ & $N E t$ & $M E$ & $D E$ \\
\hline \multicolumn{7}{c}{$\begin{array}{c}\text { Mcal/animal/dia } \\
\text { Mcal/animal/day }\end{array}$} \\
\hline 150,0 & 112,9 & 2,85 & 2,17 & 5,02 & 15,43 & 18,82 \\
175,0 & 135,2 & 3,19 & 2,24 & 5,33 & 14,87 & 18,13 \\
200,0 & 137,5 & 3,53 & 2,30 & 5,83 & 14,77 & 18,01 \\
225,0 & 179,7 & 3,86 & 2,36 & 6,22 & 14,89 & 18,16 \\
250,0 & 202,0 & 4,17 & 2,40 & 6,57 & 15,14 & 18,47 \\
275,0 & 224,3 & 4,48 & 2,45 & 6,93 & 15,47 & 18,87 \\
300,0 & 246,6 & 4,79 & 2,49 & 7,28 & 15,85 & 19,32 \\
350,0 & 291,2 & 5,37 & 2,56 & 7,93 & 16,67 & 20,33 \\
\hline
\end{tabular}




\section{Conclusões}

As exigências líquidas de energia de mantença, para os novilhos de origem leiteira, foram estimadas em $68,44 \mathrm{kcal} / \mathrm{kg}^{0,75}$. Este valor situou-se abaixo dos valores recomendados pelo NRC (1988), mas, em geral, acima dos valores estimados para bovinos de raças zebuínas e mestiços Europeu x Zebu, no Brasil.

As exigências líquidas de proteína para ganho foram semelhantes às recomendadas pelo AFRC (1993).

As exigências totais de energia metabolizável estimadas foram cerca de $10 \%$ inferiores aos níveis recomendados pelo AFRC (1993).

\section{Referências Bibliográficas}

AGRICULTURAL AND FOOD RESEARCH COUNCIL AFRC. 1991. Technical committee on response to nutrients. Voluntary Intake of Cattle. (Report, 8); Nutrition Abstracts and Reviews, 61(9):815-23.

AGRICULTURAL AND FOOD RESEARCH COUNCIL AFRC. 1993. Energy and protein requirements of ruminants. Walligford: Commonwealth Agricultural Bureaux International. 159p.

AGRICULTURAL RESEARCH COUNCIL - ARC. 1980. The nutrient requirements of ruminants livestock. London: Commonwealth Agricultural Bureaux. 351p.

BERG, R.T., BUTTERFIELD, R.M. 1976. New concepts of cattle growth. New York: Sydney University. 240p.

BOIN, C. Alguns dados sobre exigências de energia e de proteína de zebuínos. In: SIMPÓSIO INTERNACIONAL SOBRE EXIGÊNCIAS NUTRICIONAIS DE RUMINANTES, 1995, Viçosa, MG. Anais... Viçosa, MG: JARD, 1995. p. 457-65.

CASTILLO ESTRADA, L.H. Composição corporal e exigências de proteina, energia e macroelementos minerais (Ca, $\mathrm{P}, \mathrm{Mg}$, Na e $K)$, características da carcaça e desempenho do nelore e mestiços em confinamento. Viçosa, UFV, 1996. 129p. Tese (Doutorado em Zootecnia) - Universidade Federal de Viçosa, 1996.

FONTES, C. A. A. Composição corporal, exigências líquidas de nutrientes para ganho de peso e desempenho produtivo de animais zebuínos e mestiços europeu-zebu. Resultados experimentais. In: SIMPÓSIO INTERNACIONAL SOBRE EXIGÊNCIAS NUTRICIONAIS DE RUMINANTES, 1995, Viçosa, MG. Anais... Viçosa, MG: JARD, 1995, p. 419-55.

FREITAS, J.A. Composição corporal e exigências de energia e proteina de bovinos (zebuínos e mestiços) e bubalinos não castrados, em confinamento. Viçosa: UFV, 1995. 132p. Dissertação (Mestrado em Zootecnia)- Universidade Federal de Viçosa, 1995.

GARRETT, W.N. 1980. Factors influencing energetic efficiency of beef production. J. Anim. Sci., 51(6):1434-40.

GONÇALVES, L.C. Digestibilidade, composição corporal, exigências nutricionais e características das carcaças de zebuínos, taurinos e bubalinos. Viçosa: UFV, 238p. Tese (Doutorado em Zootecnia), Universidade Federal de Viçosa, 1988.

HANKINS, O.G., HOWE, P.E. 1946. Estimation of the composition of beef carcasses and cuts. Washington, D.C.: USDA (Tech. Bulletin - USDA, 926).

HARVEY, W.R. Mixed model least squares and maximum likelihood computer program (LSMLMW), versão PC-1, 1990.

JORGE, A.M. Desempenho produtivo, características de carcaça e composição corporal e da carcaça de zebuínos nãocastrados, de quatro raças, abatidos em diferentes estágios de maturidade. Viçosa: UFV, 1997. 96p. Tese (Doutorado em Zootecnia)- Universidade Federal de Viçosa, 1997.

KOCK, S.W., PRESTON, R.L. 1979. Estimation of bovine carcass composition by the urea dilution technique. J. Anim. Sci., 48(2):319-27.

LANA, R.P., FONTES, C.A.A., PERON, A.J. et al. 1992a. Composição corporal e do ganho de peso e exigências de energia, proteína e macroelementos minerais $(\mathrm{Ca}, \mathrm{P}, \mathrm{Mg}, \mathrm{Na}$, $\mathrm{K})$, de novilhos de cinco grupos raciais. 1. Conteúdo corporal e do ganho de peso em gordura, proteína e energia. $R$. Soc. Bras. Zootec., 21(3):518-27.

LANA, R.P., FONTES, C.A.A., PERON, A.J. et al. 1992b. Composição corporal e do ganho de peso e exigências de energia, proteína e macroelementos minerais $(\mathrm{Ca}, \mathrm{P}, \mathrm{Mg}, \mathrm{Na}$, $\mathrm{K})$, de novilhos de cinco grupos raciais. 2. Exigências de energia e proteína. R. Soc. Bras. Zootec., 21(3):528-37.

LANA, R.P., FONTES, C.A.A., PERON, A.J. et al. 1992c. Conteúdo do trato gastrintestinal (digesta) e sua relação com o peso corporal e ganho de peso, em novilhos de cinco grupos raciais e bovinos machos inteiros. R. Soc. Bras. Zootec., 21(3):510-7.

LOFGREEN, G.P., GARRETT, W.N. 1968. A system for expressing net energy requirements and feed values for growing and finishing beef cattle. J. Anim. Sci., 27(3):793-806.

NATIONAL RESEARCH COUNCIL - NRC. 1996. Nutrient requirements of dairy cattle. 7. ed. Washington, D.C. 158p.

NATIONAL RESEARCH COUNCIL - NRC. 1988. Nutrient requirements of dairy cattle. 6 . ed. Washington, D.C. $158 \mathrm{p}$.

NATIONAL RESEARCH COUNCIL - NRC. 1984. Nutrient requirements of beef cattle. 6. ed. Washington, D.C. 90p.

PAULINO, M.F. Composição corporal e exigências de energia, proteina e macroelementos minerais (Ca, P, Mg, Na e K) de bovinos não-castrados de quatro raças zebuinas, em confinamento. Viçosa: UFV, 1996. 80p. Tese (Doutorado em Zootecnia) - Universidade Federal de Viçosa, 1996.

PIRES, C.C., FONTES, C.A.A., GALVÃO, J.G. et al. 1993a. Exigências nutricionais de bovinos de corte em acabamento. 1. Composição corporal e exigências de proteína para ganho de peso. R. Soc. Bras. Zootec., 22(1):111-20.

PIRES, C.C., FONTES, C.A.A., GALVÃO, J.G. et al. 1993b. Exigências nutricionais de bovinos de corte em acabamento. 2. Exigências de energia para mantença e ganho de peso. $R$. Soc. Bras. Zootec., 22(1):121-32.

RYAN, W.J. 1990. Compensatory growth in cattle and sheep. Nut. Abst. Rev., 60(9):653-64.

ROGERSON, A. 1971. Food intake and energy utilization by cattle. Nut. Abst. Rev., Farham Royal, 41(4):1359-60.

SALVADOR, M. Exigências de energia e proteina para engorda de novilhos azebuados. Viçosa: UFV, 1980.70p. Dissertação (Mestrado em Zootecnia) - Universidade Federal de Viçosa, 1980. 70p.

SILVA, D.J. 1990. Análises de alimentos (Métodos químicos e biológicos). Imprensa Universitária. $165 \mathrm{p}$.

STEEL, R.G.D., TORRIE, J.H. 1960. Principles and procedures of statistics. New York: Mc Graw- Hill, Book Company. 481p.

TEIXEIRA, J.C. Exigências de energia e proteína, composição e área corporal e principais cortes da carcaça em seis grupos genéticos de bovídeos. Viçosa, UFV, 1984, 94 p. Dissertação (Mestrado em Zootecnia)-Universidade Federal de Viçosa, 1984.

VAN KEULEN, J., YOUNG, B.A. 1977. Evaluation of acidinsoluble ash a natural marker in ruminant digestibility studies. J. Anim. Sci., 44(2):282-7.

WALDMAN, R.C., TYLER, W.J., BRUNGARDT, V.H. 1971. Changes in the carcass composition of Holsteins steers associated with ration energy levels and growth. J. Anim. Sci., 32(4):611-9.

Recebido em: 25/06/97 Aceito em: 27/08/98 